Western University

Scholarship@Western

Human Environments Analysis Lab (HEAL)

$4-2016$

Free range kids? Using GPS-derived activity spaces to examine children's neighborhood activity and mobility

Janet E. Loebach

Jason A. Gilliland

Follow this and additional works at: https://ir.lib.uwo.ca/healpub 


\title{
Free Range Kids? Using GPS-Derived Activity Spaces to Examine Children's Neighborhood Activity and Mobility
}

Environment and Behavior 2016, Vol. 48(3) 42I-453

(C) 2014 SAGE Publications

Reprints and permissions: sagepub.com/journalsPermissions.nav DOI: $10.1177 / 0013916514543177$

eab.sagepub.com

(SSAGE

\section{Janet E. Loebach' and Jason A. Gilliland ${ }^{1,2,3,4}$}

\begin{abstract}
This study examines the neighborhood activity spaces (NAS) of 9- to 13-year-old children ( $n=143)$ from seven schools in London, Canada. Data from Global Positioning System (GPS) loggers worn for 7 days were used to isolate and test measures for children's pedestrian-based neighborhood activity: the maximum distance traveled from home and relative time spent in neighborhood settings. Descriptive and linear regression analyses examined the influence of individual, perceptual, and environmental factors on neighborhood use and travel. Participants spent a large portion of their out-of-school time $(75 \%)$ in their NAS. Although traveling far from home on occasion, $94.5 \%$ of children's time on average was spent within a short distance of home; participants spent little of their free time in broader neighborhood settings. School travel mode and independent mobility were among the strongest predictors of both distance traveled and time spent close to home. Perceptions of neighborhood safety, neighborhood type, and nearby land uses also influenced local activity.
\end{abstract}

\footnotetext{
'Department of Geography, Western University, London, Ontario, Canada ${ }^{2}$ School of Health Studies, Western University, London, Ontario, Canada ${ }^{3}$ Department of Paediatrics, Western University, London, Ontario, Canada ${ }^{4}$ Children's Health Research Institute, Western University, London, Ontario, Canada
}

\section{Corresponding Author:}

Janet E. Loebach, Department of Geography, Western University, II5I Richmond St., London, Ontario, Canada N6A 5C2.

Email: jeloebach@gmail.com 


\section{Keywords}

children, neighborhood, community, activity spaces, spatial behavior, mobility children's health, risk perception, recreation/leisure, school travel, urban design, GIS (geographic information system), GPS (Global Positioning System), research methods

\section{Introduction}

The freedom and opportunity to explore local neighborhood environments has been linked to a wealth of developmental and health benefits for children. Yet, both the time and license to play in neighborhood settings, particularly without the supervision of adults, has declined drastically for many children in recent decades (Fyhri, Hjorthol, Mackett, Fotel, \& Kyttä, 2011; Pooley, Turnbull, \& Adams, 2005; Shaw et al., 2012). Evidence is accruing that contemporary children are spending little of their free time in neighborhood environments, and generally not venturing very far from home on their own (Fagerholm \& Broberg, 2011; Veitch, Salmon, \& Ball, 2008; Villanueva, Giles-Corti, Bulsara, Timperio, et al., 2012; Wridt, 2010). The potential adverse health effects of the loss of local activity and mobility necessitates more work to examine children's neighborhood geographies and the factors that may broaden or limit local play and travel. Although some research to date has investigated children's neighborhood domains, the development of reliable, portable Global Positioning System (GPS) loggers provides an opportunity to move beyond subjective measures of neighborhood environments to directly measure children's true activity and mobility landscape.

This study aims to test the suitability of a new conceptual model and metrics for isolating and examining GPS-derived neighborhood activity spaces (NAS), as well as to investigate the degree to which contemporary children are spending their free time in local neighborhood settings. Specifically, this study will use GPS-based activity spaces to quantify the distance from home children are actively traveling within their neighborhood environments and the amount of free time children are spending in neighborhood settings around their homes. Preliminary descriptive and regression analyses will also examine the potential for utilizing these activity space metrics for examining how individual, perceptual, or environmental factors may influence the size of or time children spend in NAS.

\section{Neighborhood Activity as a Promoter of Healthy Development}

A child's home neighborhood has traditionally been considered a key arena during middle childhood, when a child begins to develop an interest in 
exploring the world beyond their home and family as part of their continuing development (Chawla, 1992; Hart, 1979; Moore, 1986). Starting around the age of 7 or 8 years children often begin to carve out a socio-spatial domain for activities in their neighborhood (Hart, 1979; Matthews, 1992; Spilsbury, 2005). Conquering the new complexities of local community environments breeds a sense of autonomy and competence, which can give children the confidence to continue pushing the boundaries of their neighborhood domains (Bartlett, Hart, Satterthwaite, De La Barra, \& Missair, 1999; Churchman, 2003; Gill, 2007). It is as much the process of continually expanding these domains as the challenging interactions that take place within them that have proved beneficial for healthy child development (Bartlett et al., 1999; Churchman, 2003; Gray, 2011). Children's active and playful explorations of their community settings may be in fact necessary for children to thrive (Bartlett et al., 1999; Burdette \& Whitaker, 2005; Shaw et al., 2012).

\section{Declining Levels of Neighborhood Activity and Mobility}

Children's ability to freely engage in neighborhood activity has severely declined over the past several decades. Recent meta-reviews highlight consistent and dramatic downward trends in both independent travel to school and children's overall license to play or travel around their communities, particularly when there is no adult supervision (McDonald, Brown, Marchetti, \& Pedroso, 2011; Schoeppe, Duncan, Badland, Oliver, \& Curtis, 2013; Shaw et al., 2012). One of the earliest longitudinal studies reported that unaccompanied travel to school in the United Kingdom had dropped from $72 \%$ to $7 \%$ among 7 -year-olds, and from $94 \%$ to $54 \%$ among 10 - to 11 -year-olds between 1971 and 1990 (Hillman, Adams, \& Whitelegg, 1990); a 2010 follow-up study confirmed neighborhood activity and independent mobility levels among U.K. children have continued to fall (Shaw et al., 2012). Studies in the United States and Canada echo these dramatic decreases, reporting independent and active travel to be as low as $5 \%$ of children in some cases (Buliung, Mitra, \& Faulkner, 2009; McDonald et al., 2011; McMillan, 2007). Even in other developed regions, such as New Zealand, Australia, and Northern European Countries, there have been substantial reductions in independent travel rates reported, along with considerable increases in the use of cars to escort children to school or other activity destinations (Fyhri et al., 2011; Kyttä, 2004; Veitch et al., 2008; Witten, Kearns, Carroll, Asiasiga, \& Tava'e, 2013).

\section{The Changing Landscapes of Childhood}

Downward shifts in the degree of time and freedom children are given to explore their local environments are fundamentally altering the primary 
settings and experiences of childhood. After examining inter-generational changes in children's activity in an Amsterdam neighborhood, Karsten (2005) suggests that contemporary landscapes of childhood have changed so dramatically from previous generations as to necessitate new classifications of childhood play experience. Play among earlier generations was often synonymous with "outdoor play," the majority of children's activities taking place in the public outdoor settings of the neighborhood (Karsten, 2005). While some contemporary children still demonstrated this type of "outdoor" childhood, many others were classified as having "indoor" or "backseat" childhoods due to the vast amount of time spent indoors or being chauffeured in vehicles to various activities (Karsten, 2005).

Similar transformations in childhood activities and settings are now being documented in many developed countries, precipitated by a number of cultural changes. Increased availability of home-based entertainment such as television, computers, and video games (Clements, 2004; Copperman \& Bhat, 2009; Karsten, 2005; Witten et al., 2013), coupled with parents' heightened concern for providing "safer," supervised activities (Clements, 2004; Gaster, 1991; Gray, 2011; Valentine \& McKendrck, 1997), have made indoor activities more appealing to both children and parents. Many parents no longer view the neighborhood as a safe play space for children; fear of stranger abduction or safety concerns due to traffic and bullies can lead parents to accompany children on neighborhood excursions or keep them indoors all together (Clements, 2004; Mikkelsen \& Christensen, 2009; Pooley et al., 2005; Shaw et al., 2012). Family schedules and rhythms have also changed to accommodate parental commuting patterns, as well as children's increased involvement in structured out-of-school activities (Copperman \& Bhat, 2009; Gray, 2011; Mackett, Brown, Gong, Kitazawa, \& Paskins, 2007; Witten et al., 2013). The net result is an increase in the time children spend indoors in private settings or in vehicles being driven to a range of organized activities, many of which are now outside of their immediate neighborhood (Karsten, 2005; Mikkelsen \& Christensen, 2009; Pooley et al., 2005). The public, outdoor settings of the "street" and neighborhood have become inaccessible or infrequent domains for many children (Karsten, 2005; Mikkelsen \& Christensen, 2009; Spilsbury, 2005).

\section{The Negative, Not Neutral, Effects of Restricted Activity and Mobility}

Restricting neighborhood activity and mobility typically sprouts from a desire to protect children from risk; however, there is little awareness among caregivers of the potential negative impact of these protective strategies for 
children's health and development. Children whose neighborhood activity is more restricted tend to venture outside less often, engage in shorter periods of outdoor play and exhibit lower levels of physical activity (Page, Cooper, Griew, \& Jago, 2010; Prezza et al., 2001; Shaw et al., 2012). Limiting children's interaction with the diverse physical and social environments of the neighborhood can also obstruct the development of personal and social skills, as well as reduce their ability to develop healthy community relationships and effectively engage in neighborhood life (Mikkelsen \& Christensen, 2009; Rissotto \& Giuliani, 2006). Reduced exposure to local places can weaken a child's comfort in public settings, their sense of environmental competence and even their sense of self (Prezza \& Pacilli, 2007; Rissotto \& Tonucci, 2002; Spilsbury, 2005). Reduced neighborhood activity may have significant adverse effects for children's healthy development.

\section{Conceptual Model: Children's NAS}

Although generally receiving little research attention, there has been a small thread of work attempting to capture and describe the neighborhood territories that children use in the course of their daily routines. Children's neighborhood spaces have been alternately characterized in these studies as home ranges, territorial ranges, neighborhood domains, activity ranges, and action- or activity spaces. The term activity space will be used for this study to refer to the full spatial territory that children utilize in the course of their everyday activities.

Most work to date has measured or characterized children's NAS primarily in spatial terms, using metrics such as distance or area; few have included a temporal component that addresses when and for how long children use these domains, a component necessary to examine children's habitual use of their NAS.

To create appropriate NAS metrics for this study, we draw upon Moore's (1986) classic study of British children's use of neighborhood environments. Moore recognized that children do not spend time equally within all areas of their home range and proposed a conceptual model of nested "ranges" (activity spaces) to characterize the spatial and temporal differences in children's use of their local environments (see Figure 1). A child's habitual range encompasses the settings centered around the home that a child can easily access, and which they utilize on an almost daily basis. A child's frequented range, broader than their habitual range, includes those neighborhood spaces accessed periodically when granted the time and freedom to do so. Moore suggests that this frequented range is usually bounded by both parental restrictions and physical constraints, such as busy roads. The third territory, a child's occasional range, represents the absolute edges of a child's 


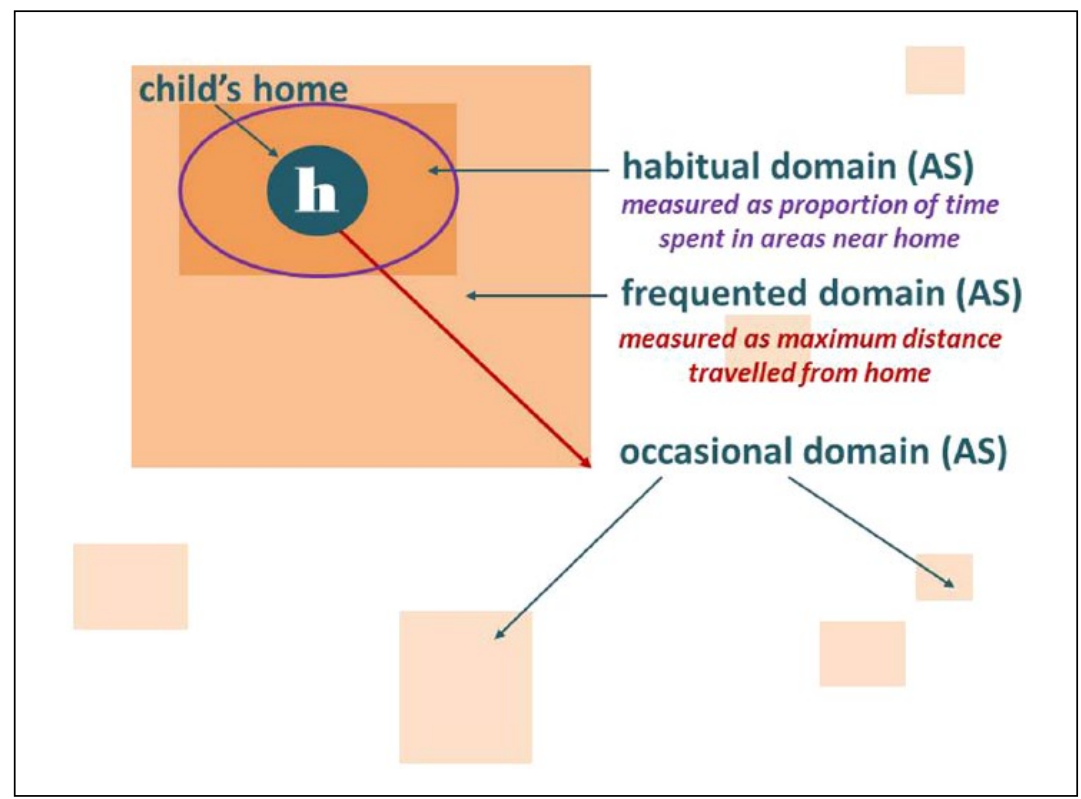

Figure I. Moore's model of childhood domains (AS) with study metrics. Note. AS = activity spaces.

independent territory at a given time and includes those places that a child accesses infrequently or via public transportation, and therefore, no longer represents a strictly pedestrian-based territory. The size of these activity spaces can be highly variable, depending on factors such as child age, gender, or parental confidence in a child's ability to negotiate territories beyond home (Matthews, 1992; Moore, 1986; Spilsbury, 2005; Villanueva, Giles-Corti, Bulsara, McCormack, et al., 2012).

As conceptualized by Moore, the nested domains of the habitual and frequented ranges represent the activity space commonly used by children, on foot or bicycle, in the course of their daily and weekly routines (see Figure 1). The outer periphery of this pair of ranges aligns with the boundaries of the pedestrian-based NAS sought out in this study. This pair of spatial ranges will be referred to as a child's habitual activity space and frequented activity space.

\section{Capturing and Measuring Children's NAS}

Accurately capturing children's NAS is a difficult endeavor, particularly as these territories present moving targets with shifting boundaries. Previous 
studies have utilized a range of strategies and metrics to describe these fluid domains, including child- or parent-drawn maps, interviews, focus groups, and neighborhood walking tours (Loebach \& Gilliland, 2010; MacDougall, Schiller, \& Darbyshire, 2009; Spilsbury, 2005; Veitch et al., 2008). Recent advancements in portable GPS monitoring technology (e.g., GPS loggers or GPS-enabled cell phones) are now allowing researchers to directly observe children's spatial activity and mobility patterns over an extended time. This study utilizes portable GPS loggers combined with survey and local built environment data to capture and measure children's NAS, and examine the factors that may support or limit local activity and travel.

\section{Method}

\section{Recruitment and Data Collection}

This study utilizes data gathered for the STEAM (Spatio-Temporal Environment and Activity Monitoring) project (steamproject.ca), a study designed to examine the effects of the built environment on children's healthrelated behaviors. Four urban and three suburban elementary schools from London, Canada, participated during April and May of 2010 and 2011. All children in Grades 5 to 8 (approximately 9-13 years of age) were eligible to participate. The response rate from all schools was $49 \%$, resulting in an initial sample size of 220 children.

Participants completed a 7-day multi-tool protocol to document their neighborhood activity and mobility patterns. Participants wore passive GPS monitors (VGPS-900 by Visiontac) that recorded a spatial coordinate for each second during all waking hours. Both child participants and their parents also completed comprehensive surveys on children's habitual neighborhood activities, mobility behaviors, and environmental perceptions.

GPS tracks from participants were used to create measures of children's NAS. To ensure a GPS data set represented a valid snapshot of a child's NAS, only data sets with at least 3 hrs (?) of out-of-school wear (based on a 7-hr school day) on at least two weekdays, and a minimum of $4 \mathrm{hr}$ on at least one weekend day, were included in the analysis. Without a common standard for GPS wear time, validity criteria were guided by current standards for accelerometer wear time, namely $10 \mathrm{hr}$ of recording for a minimum of 3 days (Cliff, Reilly, \& Okely, 2009; Colley, Gorber, \& Tremblay, 2010; Penpraze et al., 2006). Of the original 220 participants, 144 (66\%) met the minimum requirements. Most final participants far exceeded data minimums; the median volume of out-of-school GPS data over 7 days was $42.1 \mathrm{hr}$, and the minimum was over $18 \mathrm{hr}$. The median number of valid weekdays and 
weekend days were 4.0 and 2.0 days, respectively. Preliminary data analysis identified a single outlier that was subsequently removed from the sample (Pallant, 2011) leaving a final sub-sample size of 143 children, $75.6 \%$ of which also had a completed parent survey.

\section{Outcome Variables: Measures of NAS}

This study was specifically interested in the neighborhood settings children travel to using pedestrian or "active" means (e.g., on foot, bicycle, skateboard). A child's NAS is therefore defined by all out-of-school GPS tracks that originated from home and to which they traveled without a vehicle. Using this definition, two dimensions of children's NAS are used as the primary outcome measures: (a) relative size of the NAS (spatial metric) and (b) relative amount of time spent within the zones of the NAS (spatio-temporal metric).

Relative size of the NAS. The "maximum distance traveled from home" was selected as the primary spatial metric to measure relative NAS size. A maximum path distance (MPD) was created for each participant by converting all GPS points within their NAS to a raster set (based on a $20 \mathrm{~m}$ cell), then applying the Cost Distance tool within ArcGIS v10.0 to calculate the longest distance traveled from the child's home along all possible continuous paths created by a series of adjacent raster cells containing any GPS points (see Figures 2 and 3 for illustrations of the cost distance tool application). MPD, representing the distance to the extreme edge of the pedestrian-based NAS, can then be used as a measure of a child's frequented activity space, the space which they are allowed to access but which they do not use on a habitual basis (see Figure 1).

Relative time spent in the NAS. To examine the relative time each child spent in their NAS, and at various distances from home, a "locational" filter was applied to all GPS points, assigning each to a set of concentric circular buffers around the home. Buffers were set at $400 \mathrm{~m}$ increments up to $1,600 \mathrm{~m}$ (1 mile), after which all points were classified as "greater than 1,600 m" (see Figures 2 and 4 to see the application of the locational filter). As each GPS point represents one second of time, totaling GPS points within a buffer provides a measure of time spent at that relative distance from home. These spatio-temporal measures highlight the child's habitual activity space, indicating, by virtue of the amount of time spent at various distances from home, the size of the NAS which they inhabit on a more habitual basis. 


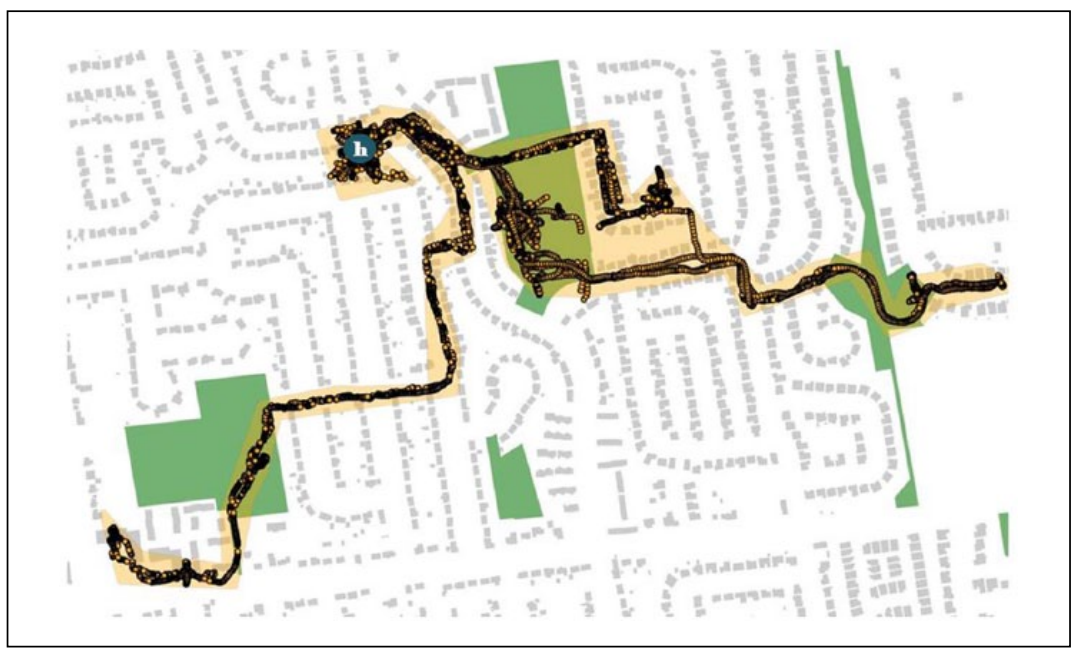

Figure 2. Hypothetical GPS defining a child's NAS.

Note. GPS = Global Positioning System; NAS = neighborhood activity space.

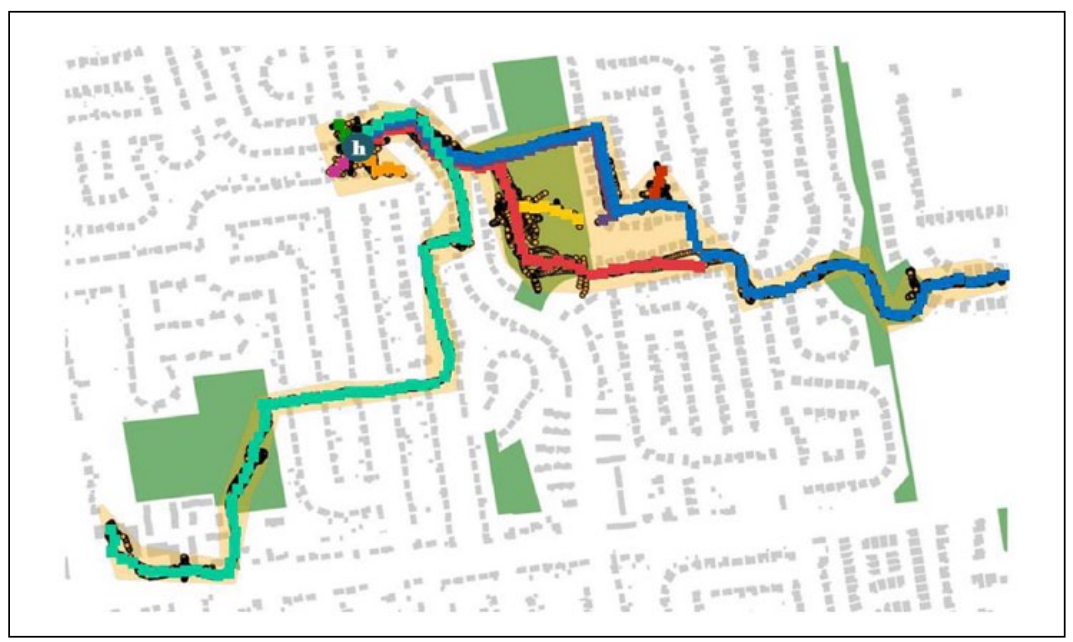

Figure 3. Hypothetical illustration of development of raster-based measure of MPD.

Note. MPD = maximum path distance.

A second filter was applied to isolate the GPS points within the NAS that were likely recorded inside the child's home. Field testing of the GPS loggers 


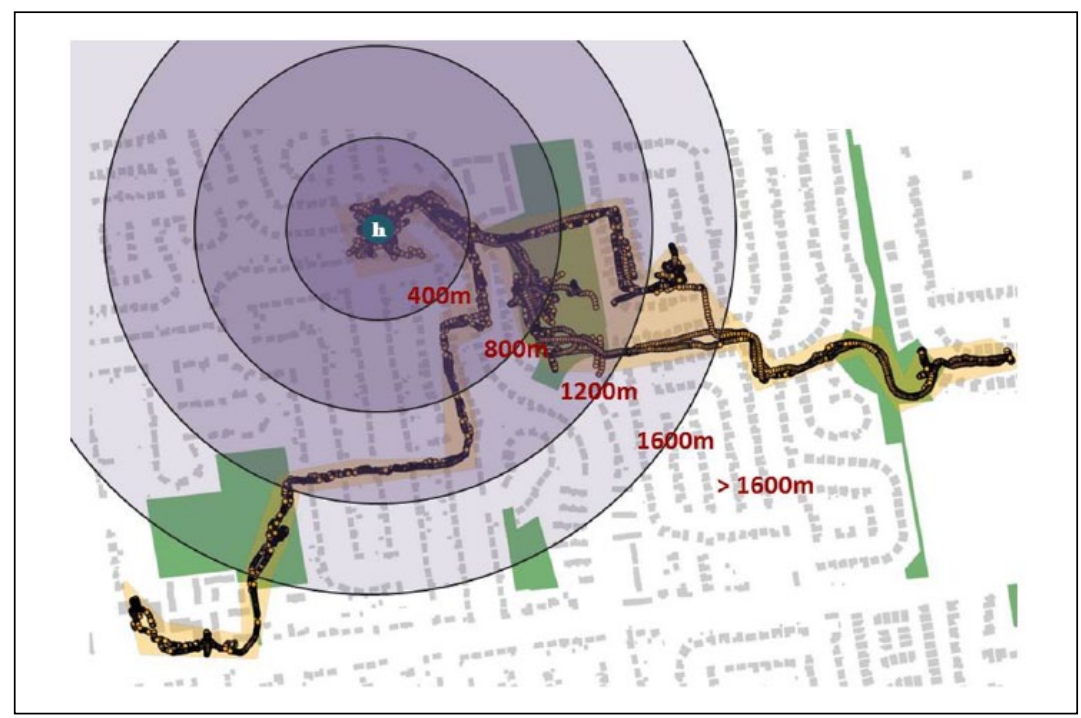

Figure 4. Hypothetical illustration of assignment of GPS points to fixed distance buffers.

Note. GPS = Global Positioning System.

found the units exhibited high levels of precision in recorded spatial coordinates when outdoors (a 3D satellite fix and a horizontal dilution of precision [HDOP] less than $1.2 \mathrm{~m}$ ), but very poor precision when indoors and out of range of tracking satellites (only a $2 \mathrm{D}$ satellite fix and HDOP greater than 2 $\mathrm{m})$. To estimate the volume of time spent indoors at home, all GPS points within a $10 \mathrm{~m}$ radius of the centroid of the home, regardless of precision level, were assigned as "indoors at home," as well as all points within a 150 $m$ radius that met the criteria for "poor precision."

\section{Independent Variables: Factors Influencing Neighborhood Activity and Mobility}

This work is carried out within a socio-ecological framework that recognizes multiple spheres of influence on children's behaviors and health outcomes (Macintyre \& Ellaway, 2000; Sallis \& Glanz, 2006). A number of compositional and contextual factors may be restricting children's activity in neighborhood environments, or keeping them more home-centered. Factors identified in the literature to date can be grouped into three categories: (a) 
individual-level factors, (b) perceptions of the local environment, and (c) built environment characteristics.

Individual-level factors. Individual-level factors shown to be influential in other studies of neighborhood play and mobility were chosen as independent variables for this study, including child age and gender, travel mode and distance to school, home neighborhood type, and degree of independent mobility (Fyhri \& Hjorthol, 2009; Kerr, Frank, Sallis, \& Chapman, 2007; Larsen et al., 2009; Mackett et al., 2007; McDonald, 2007b; Page et al., 2010; Spilsbury, 2005; Veitch et al., 2008; Villanueva, Giles-Corti, Bulsara, McCormack, et al., 2012). For this exploratory examination of influential factors, variables were grouped into dichotomous categories: age group (9-11 years/12-13 years), gender (females/males), travel mode to school (active traveler/non-active traveler), distance from home to school (less than 1,600 $\mathrm{m} /$ greater than 1,600 m), neighborhood type (urban/suburban), and independent mobility (high/low). Children were labeled as "active travelers" to school if survey responses indicated an "active" mode at least 1 day per week. Children were considered to have "low independent mobility" if parent surveys indicated the child is restricted from traveling in the neighborhood without an adult.

Perceptual factors. Previous research has demonstrated that parent and child perceptions of the barriers or risks presented by the local environment, whether evidence-based or not, can influence children's neighborhood activity (Johansson, 2006; Kerr et al., 2006; MacDougall et al., 2009; Panter, Jones, \& van Sluijs, 2008; Shaw et al., 2012; Timperio, Crawford, Telford, \& Salmon, 2004; Witten et al., 2013). Two neighborhood perception variables were selected for both children and parent groups, perceptions of neighborhood risk and of the accessibility of local recreational amenities. Surveyed parents or children who "agreed" or "strongly agreed" that the neighborhood presented risks to child safety were considered to have a "high perception of risk." Parents or children who "agreed" or "strongly agreed" that local play was difficult because amenities are too far from home were considered to perceive "low access to local recreation."

Built environment factors. Objective environmental measures previously found to influence children's local activity or mobility were used in this study: population density (population per $\mathrm{km}^{2}$ ), youth population density (population aged 5-14 years per $\mathrm{km}^{2}$ ), residential density (residential units per $\mathrm{km}^{2}$ ), proportions of primary land uses (commercial, residential, institutional, industrial, and agricultural land area within the buffer), traffic volume (maximum 
count per hour on any street segment within the buffer), intersection density (intersection count per $\mathrm{km}^{2}$ ), and public recreational opportunity density (count per km²; Fagerholm \& Broberg, 2011; Frank \& Engelke, 2001; Kerr et al., 2007; Larsen et al., 2009; Panter et al., 2008; Schoeppe et al., 2013; Villanueva, Giles-Corti, Bulsara, Timperio, et al., 2012). Environmental measures were derived for each participant using data obtained from the City of London and Statistics Canada (2006). Measures were created in ArcGIS using circular buffers centered on a child's home at each of four radial buffer distances: 400, 800, 1,200, and 1,600 m.

\section{Analysis}

Descriptive and regression analyses were conducted to examine the relative size of children's NAS and the relative time spent in their NAS at various distances from home. Analyses also explored the potential influence of individual, perceptual, and environmental factors on neighborhood behaviors; the small sample size precluded comprehensive multivariate analyses but allows for an initial examination of patterns between sample subgroups. Independent-samples $t$ tests were conducted to compare differences in means for each NAS measure within each of the demographic categories, as well as within child and parent perception variables. Pearson's correlations examined relationships between outcome variables and each of the built environment measures at the chosen buffer distances. Correlation matrices were used to examine potential relationships between outcome variables (NAS measures) and any of the individual, perceptual, or environmental variables, as well as any covariance between independent variables.

In addition to examining general patterns within each NAS measure, a series of linear regression analyses were performed in SPSS v.17 to explore associations between all of the selected socio-environmental variables and two dependent variables, one spatial and one spatio-temporal: MPD traveled (relative NAS size) and proportion of time spent within $400 \mathrm{~m}$ of home (relative time spent in NAS close to home).

All individual, perceptual, and built environment variables were initially included in all models as independent variables. Separate models, however, were run for each dependent variable to examine the influence of built environment conditions at different buffer distances; one set of models considered conditions found within $800 \mathrm{~m}$ of home, the second set those found within 1,600 m. Independent variables were added into models simultaneously and then in hierarchical combinations; the hierarchical process did not affect the values produced by the models, therefore all relevant variables were added into final models simultaneously (Pallant, 2011). Iterations of 
independent variable combinations were added into models to reveal the variable set with the highest explanatory power; correlation matrices and results from early regression models were used to refine the variable combinations included in final models.

\section{Results}

\section{Descriptive Statistics}

Of the final participant sample of 143 children, the median age was 11.0 years, $65.3 \%$ were female, and $55.6 \%$ were from urban neighborhoods. One half $(50.3 \%)$ reported traveling to or from school by active means at least 1 day a week. The mean network distance from home to school was large $(M=$ $1,877 \mathrm{~m}, S D=1,532 \mathrm{~m})$, but over half of the children $(58.0 \%)$ lived within $1,600 \mathrm{~m}$ (1 mile) of their school. Most participants (86.7\%) had low levels of independent neighborhood mobility; only $13.3 \%$ of children were not subject to any mobility restrictions. A similar proportion of urban (60\%) and suburban $(65 \%)$ children had low independent mobility (IM), but a higher percentage of girls $(67.0 \%)$ were subject to mobility restrictions than boys $(53.1 \%)$, and a greater proportion of younger children $(67.8 \%)$ had low IM versus the older group $(53.6 \%)$.

Time spent in NAS proportional to all out-of-school time. Participants spent, on average, over three quarters of their total out-of-school time $(M=76.3 \%$, $S D=15.9 \%$ ) in their pedestrian-based NAS. This average did not vary significantly when stratified by any of the individual-level categories. One quarter of their day, outside of school time, is therefore spent in environments that they reach, by choice or by necessity, via motorized transport. Over half $(52 \%)$ of the participants spent at least $80 \%$ of their out-of-school time within their NAS. This represents a very high proportion of their overall leisure time; most children spent the vast majority of this free time either at home or in settings they traveled to by "active" means.

Of this time spent within their NAS, analysis suggests that children spent $51 \%$ on average $(S D=25.0 \%)$ indoors at home, with one quarter spending more than $70 \%$ of their total NAS time inside at home.

\section{Relative Size of NAS: Maximum Distance Traveled}

Individual-level differences. The average distance from the home to the outer boundary of the child's NAS was relatively long $(M=980 \mathrm{~m}, S D=726 \mathrm{~m})$ and illustrates that many children walked or biked a long distance from their 
Table I. Mean Differences in Maximum Path Distance $(\mathrm{m})$ Traveled Among Demographic Groupings.

\begin{tabular}{|c|c|c|c|c|c|c|}
\hline \multirow{2}{*}{$\begin{array}{l}\text { Demographic categories } \\
\text { (Group I/Group 2) }\end{array}$} & \multirow[b]{2}{*}{$n$} & \multirow{2}{*}{$\frac{\text { Group I }}{M(S D)}$} & \multirow{2}{*}{$\frac{\text { Group } 2}{M(S D)}$} & \multirow[b]{2}{*}{$d f$} & \multirow[b]{2}{*}{$t^{\mathrm{a}}$} & \multirow[b]{2}{*}{$p$} \\
\hline & & & & & & \\
\hline Age group (9-1 $1 / 12-13$ years) & $87 / 56$ & $903.8(616.5)$ & I,097.4 (86I.7) & 141 & -1.57 & .148 \\
\hline Gender (Female/male) & $94 / 49$ & $927.3(676.7)$ & $1,080.0(809.6)$ & $14 \mid$ & -1.2 & .234 \\
\hline Neighborhood type (Urban/suburban) & $79 / 64$ & I,070.8 (746.6) & $867.0(688.4)$ & $14 \mid$ & 1.68 & .095 \\
\hline $\begin{array}{l}\text { Travel mode to school (Active/non- } \\
\text { active) }\end{array}$ & $72 / 71$ & I,3। $2.8(739.6)$ & $641.8(532.8)$ & $|4|$ & 6.22 & $.000^{* * * *}$ \\
\hline $\begin{array}{l}\text { Distance home to school } \\
(<1,600 />1,600 \mathrm{~m})\end{array}$ & $83 / 60$ & I, I $37.2(738.0)$ & $761.6(653.9)$ & $|4|$ & 3.15 & $.002 * *$ \\
\hline $\begin{array}{l}\text { Parent-awarded independent mobility } \\
\text { (Low IM/high IM) }\end{array}$ & $89 / 19$ & $837.1(600.3)$ & I,625.7 (921.0) & 21.4 & -3.57 & $.002^{* * *}$ \\
\hline
\end{tabular}

alndependent-samples $t$ test (two-tailed).

$*_{p}<.05$. $*_{p}<.01$. $*^{*} *_{p}<.001$.

home at least once during the week. Over half of the children (57\%) traveled more than $800 \mathrm{~m}$ from their homes on at least one occasion. Maximum Path Distance (MPD), however, varied greatly among participants and there were many children at both extremes of the distance spectrum; $17 \%$ traveled at least $1,600 \mathrm{~m}$ from home, but almost an equal proportion (18\%) traveled only $200 \mathrm{~m}$ from home or less.

The average MPD for active travelers to school was almost $700 \mathrm{~m}$ more than their non-active peers, and students living within 1,600 $\mathrm{m}$ of their school traveled $375 \mathrm{~m}$ more on average than those who live further away (see Table 1). Of the children who live within $1,600 \mathrm{~m}$ of their school, $80.0 \%$ had their school encompassed within their NAS, indicating active travel to school at least once during the study week. Conversely, only $11.6 \%$ of children living beyond $1,600 \mathrm{~m}$ of their school had the school location included within their NAS. The school was the furthest traveled destination for one third $(32.9 \%)$ of children whose school location fell within their NAS; the remaining two thirds traveled to destinations further away. The average MPD for children with high IM was almost double that of participants with lower mobility. There were no statistically significant differences in the average MPD by age group, gender, or neighborhood type.

Perceptual-level differences. There were no significant differences in average MPD based on either a child's or their parent's perception of neighborhood access to recreational opportunities. However, both child and parent perceptions of neighborhood risk appeared to exert some influence; children who perceived lower levels of risk traveled significantly further on average $(M=$ 
$1,048.4 \mathrm{~m}, S D=816.5 \mathrm{~m}), t(110)=2.3, p=.035$, than those who perceived more risk $(M=793.9 \mathrm{~m}, S D=530.1 \mathrm{~m})$. Similarly, children of parents who perceived lower levels of risk traveled $300 \mathrm{~m}$ further on average $(M=1,209.6$ $\mathrm{m}, S D=878.0 \mathrm{~m})$ than children whose parents perceived higher risk $(M=$ $896.6 \mathrm{~m}, S D=618.5 \mathrm{~m}), t(105)=2.12, p=.036$.

Environmental-level differences. Of the built environment variables within 400 and $800 \mathrm{~m}$ of the child's home, only the proportion of agricultural land within $800 \mathrm{~m}$ was correlated with MPD (see Table 2). Built environment variables within 1,200 and 1,600 m exhibited stronger relationships; the proportion of commercial $(+)$, residential $(+)$, and agricultural $(-)$ land within both buffers all correlated to distance traveled. Intersection density was the only other environmental variable associated with MPD; a greater density within the broader neighborhood related to longer maximum distances traveled.

\section{Relative Time in NAS: Proportion of Time Spent Within Fixed Distances From Home}

Individual-level differences. The proportion of all NAS points within each 400 $\mathrm{m}$ distance buffer around each child's home was calculated, revealing that participants carried out the vast majority of their pedestrian-based activity close to home. On average, almost $95 \%$ of all time spent within their NAS was within $400 \mathrm{~m}$ of home, and $98 \%$ was within $800 \mathrm{~m}$ of home. Close to one third $(29.4 \%)$ of participants spent all of their time in their NAS within 400 $\mathrm{m}$ of home, and almost two thirds (60.8\%) spent $100 \%$ of their NAS time within $800 \mathrm{~m}$. Children in the younger age group (9-11 years) spent a significantly greater proportion of their time within $400 \mathrm{~m}$ of home, as did nonactive travelers, children who live more than $1,600 \mathrm{~m}$ from school, and those with low IM (see Table 3). Average time spent within $400 \mathrm{~m}$ of home was not statistically different by gender or neighborhood type.

Participants spent little to no part of their leisure time beyond $800 \mathrm{~m}$ of home, on average only $2.3 \%$ of their NAS time ( 45 min per week on average; $S D=5.5 \%$ ); time spent beyond $1,600 \mathrm{~m}$ of home drops further to $0.4 \%$ (about $10 \mathrm{~min}$ on average per week; $S D=2.3 \%$ ). Again, older children, active travelers, children who live within 1,600 $\mathrm{m}$ of school, and those with higher IM were on average more likely to venture beyond $800 \mathrm{~m}$ of home (see Table 4). For time spent beyond 1,600 $\mathrm{m}$ of home, however, only age group exhibits significant mean differences, with older children spending significantly more time $(M=1.0 \%, S D=3.5 \%)$ at these more extreme distances than their younger peers $(M=0.0 \%, S D=0.0 \%), t(55)=-2.19, p=.033$. 
Table 2. Significant Correlations (Pearson's $r$ ) With Built Environment Measures at Varying Buffer Distances.

\begin{tabular}{|c|c|c|c|}
\hline & \multirow[b]{2}{*}{$\begin{array}{l}\text { Maximum path } \\
\text { distance traveled }\end{array}$} & \multicolumn{2}{|c|}{ Proportion of time spent } \\
\hline & & $\begin{array}{l}\text { within } 400 \mathrm{~m} \\
\text { of home }\end{array}$ & $\begin{array}{l}\text { beyond } 800 \mathrm{~m} \\
\text { of home }\end{array}$ \\
\hline \multicolumn{4}{|c|}{ Built environment within $400 \mathrm{~m}$ buffer } \\
\hline Residential density & - & - & - \\
\hline$\%$ commercial & - & - & - \\
\hline$\%$ institutional & - & - & - \\
\hline$\%$ residential & - & - & - \\
\hline$\%$ agricultural & - & - & - \\
\hline Intersection density & - & - & - \\
\hline \multicolumn{4}{|c|}{ Built environment within $800 \mathrm{~m}$ buffer } \\
\hline Residential density & - & $-0.20 *$ & $+0.22^{* *}$ \\
\hline$\%$ commercial & - & - & $+0.17^{*}$ \\
\hline$\%$ institutional & - & - & - \\
\hline$\%$ residential & - & - & - \\
\hline$\%$ agricultural & $-0.17^{*}$ & $+0.17^{*}$ & - \\
\hline Intersection density & - & - & - \\
\hline \multicolumn{4}{|c|}{ Built environment within $1,200 \mathrm{~m}$ buffer } \\
\hline Residential density & - & $-0.21 *$ & $+0.23 * *$ \\
\hline$\%$ commercial & $+0.24 * *$ & $-0.23 * *$ & $+0.22 * *$ \\
\hline$\%$ institutional & - & - & - \\
\hline$\%$ residential & $+0.20 *$ & - & - \\
\hline$\%$ agricultural & $-0.19 *$ & $+0.18^{*}$ & - \\
\hline Intersection density & $+0.22 * *$ & $-0.19 *$ & - \\
\hline \multicolumn{4}{|c|}{ Built environment within I,600 m buffer } \\
\hline Residential density & - & $-0.20 *$ & $+0.21 *$ \\
\hline \% commercial & $+0.20 *$ & $-0.24 * *$ & $+0.27 * *$ \\
\hline$\%$ institutional & - & - & - \\
\hline$\%$ residential & $+0.20 *$ & - & - \\
\hline$\%$ agricultural & $-0.19 *$ & $+0.19 *$ & - \\
\hline Intersection density & $+0.20 *$ & $-0.25 * *$ & $+0.20 *$ \\
\hline
\end{tabular}

Note. Some variables were never significant and thus omitted: Population density, youth population density, \% industrial and \% recreational land uses, maximum traffic count, and recreational facility density.

$* p<.05 . * * p<.01$.

Perceptual-level differences. The proportion of time children spent within 400 $\mathrm{m}$ of home was not significantly associated with parents' perceptions of neighborhood risk or of access to local recreational amenities. However, 
Table 3. Mean Differences in Proportion of Time Spent Within $400 \mathrm{~m}$ of Home (\%) Among Demographic Groupings.

\begin{tabular}{|c|c|c|c|c|c|c|c|}
\hline & & & Group I & Group 2 & & & \\
\hline Demographic categories & Group I/Group 2 & $n$ & $M(S D)$ & $M(S D)$ & $d f$ & $t^{\mathrm{a}}$ & $p$ \\
\hline Age group & $9-11 / 12-13$ years & $87 / 56$ & $96.5(5.1)$ & $91.4(10.6)$ & 141 & 3.82 & $.00 I^{* *}$ \\
\hline Gender & Female/male & $94 / 49$ & $95.0(7.6)$ & $93.6(8.9)$ & $14 \mid$ & 0.98 & .332 \\
\hline Neighborhood type & Urban/suburban & $79 / 64$ & $94.4(7.2)$ & $94.6(9.1)$ & $14 \mid$ & -0.1 & .921 \\
\hline Travel mode to school & Active/non-active & $72 / 71$ & $91.2(9.5)$ & $97.8(4.4)$ & 141 & -5.32 & $.000 * * * *$ \\
\hline Distance home to school & $<1,600 />1,600 \mathrm{~m}$ & $83 / 60$ & $92.6(9.3)$ & $97.2(4.9)$ & $|4|$ & -3.46 & $.000 * * *$ \\
\hline $\begin{array}{l}\text { Parent-awarded } \\
\text { independent mobility }\end{array}$ & Low IM/high IM & $89 / 19$ & $95.5(6.4)$ & $87.3(10.6)$ & 20.8 & 3.22 & $.004^{* *}$ \\
\hline
\end{tabular}

alndependent-samples $t$ test (two-tailed).

$*_{p}<.05$. **p $<.01$. *** $p<.001$.

children who perceived higher levels of neighborhood risk spent significantly more of their time closer to home $(M=96.3 \%, S D=5.7 \%)$ than children who perceived less risk $(M=93.7 \%, S D=8.7 \%), t(109)=-1.997, p=.048$. Children who perceived local recreational facilities as "too far from home" spent significantly more time within $400 \mathrm{~m}$ of home $(M=97.7 \%, S D=8.1 \%)$ than those who disagreed $(M=94.0 \%, S D=5.2 \%), t(29.9)=-2.57, p=.016$. Neither child nor parent perceptions of the neighborhood were significantly associated with the proportion of time children spent in settings beyond 800 $\mathrm{m}$ of home.

Environmental-level differences. The proportion of time children spent within $400 \mathrm{~m}$ of home was not significantly related to any of the selected built environment conditions within $400 \mathrm{~m}$ of home (see Table 2). Only residential density ( () and proportion of agricultural land (+) within an $800 \mathrm{~m}$ buffer correlated with the proportion of time spent close to home.

Environmental conditions within both 1,200 and 1,600 m, however, were more strongly tied to time spent near home. Residential density at both buffer distances was negatively correlated with time spent within $400 \mathrm{~m}$ of home; the lower the density of homes in the broader neighborhood, the more likely to find the child close to home. A lower proportion of commercial land, a higher percentage of agricultural land and a lower density of intersections beyond 1,200 $\mathrm{m}$ all correlated with time spent within $400 \mathrm{~m}$ of home.

The proportion of time spent in neighborhood zones beyond $800 \mathrm{~m}$ of home was influenced by the same built environment conditions influencing time spent closer to home, but the proportion of commercial land within 800 $\mathrm{m}$ also becomes significant; more nearby commercial properties correlated with more time spent in the neighborhood further from home. 


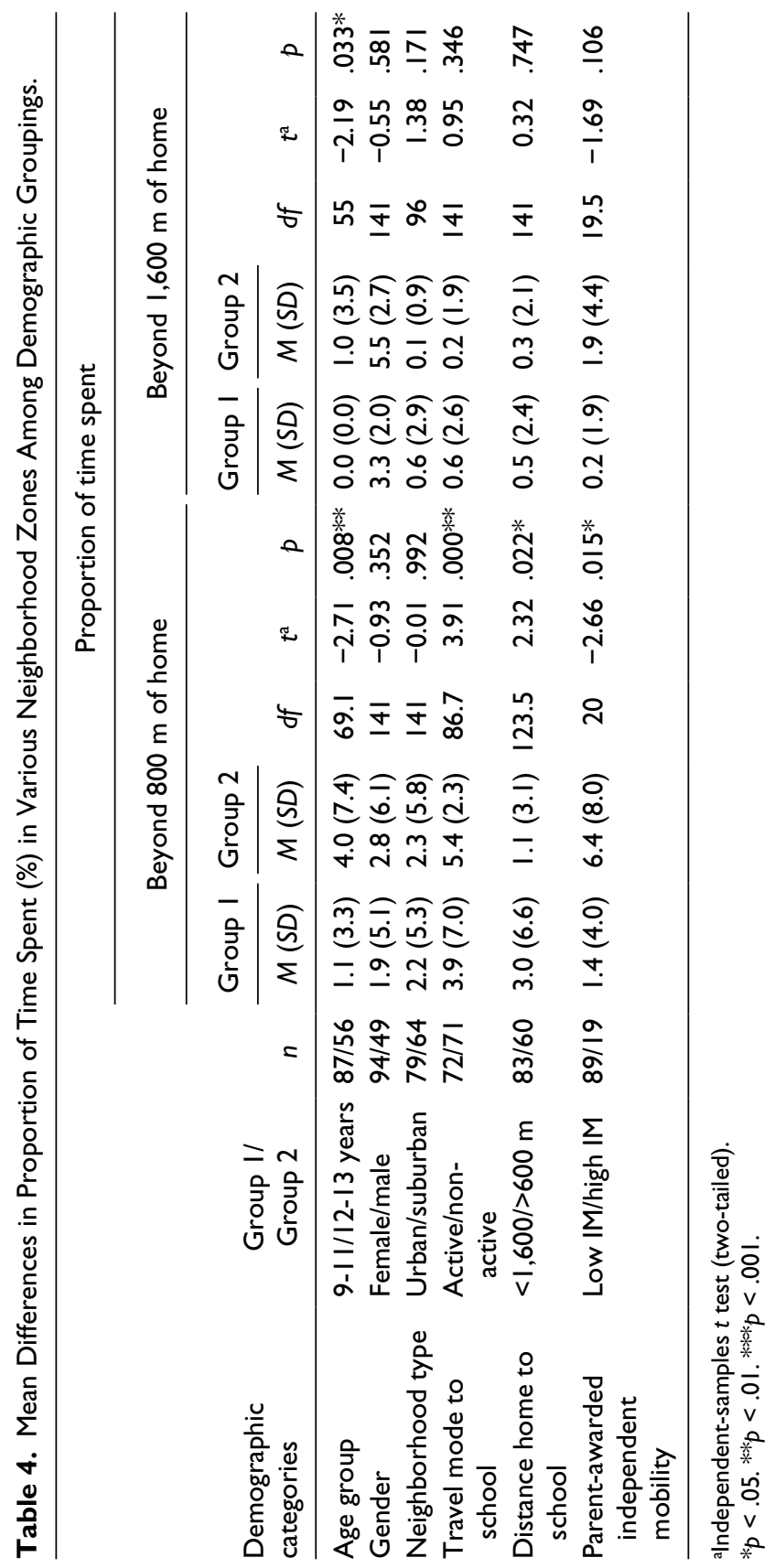


Table 5. Linear Regression Model I: Maximum Path Distance Traveled.

\begin{tabular}{lccc}
\hline Independent variables & Unstandardized $\beta$ & Standardized $\beta$ & $95 \% \mathrm{Cl}$ \\
\hline $\begin{array}{l}\text { Neighborhood type (urban/ } \\
\text { suburban) }\end{array}$ & -251.32 & $-0.17^{*}$ & {$[-503.1,0.25]$} \\
$\begin{array}{l}\text { Travel mode to/from school (active/ } \\
\text { non-active) }\end{array}$ & -658.94 & $-0.46^{* * * *}$ & {$[-896.2,-421.69]$} \\
$\begin{array}{l}\text { Parent-reported independent } \\
\text { mobility (low IM/high IM) }\end{array}$ & 343.68 & $0.19^{*}$ & {$[34.09,653.27]$} \\
$\begin{array}{l}\text { Parent perception: Safety (safe/risky) } \\
\% \text { commercial land within } 800 \mathrm{~m}\end{array}$ & -350.12 & $-0.23^{* *}$ & {$[-609.17,-91.08]$} \\
$n=104$ & 16.50 & $0.09 \dagger$ & {$[-13.86,46.86]$} \\
Adjusted $r^{2}=.314$ & & & \\
\hline
\end{tabular}

$t_{p}<.10 . * p<.05 . * * p<.01 . * * * p<.001$.

\section{Regression Analyses}

Linear regression models were created for each of the outcome variables to further explore the individual, perceptual, and environmental factors that may predict the relative size of children's NAS, and the time spent within different NAS zones.

Model I:MPD traveled. No single variable or set of variables (individual, perceptual, or environmental) was able to predict a significant degree of variance among the maximum distances traveled. Individual-level factors (neighborhood type, travel mode to school, and parent-reported IM), however, explained more of the variance than any other variable set (see Table 5). The model that explained the highest degree of variance (adjusted $r^{2}=.314$ ) included a combination of individual, perceptual, and environmental factors. Travel mode to school was by far the strongest predictor of MPD traveled, forecasting that active travelers venture further from home on average. Neighborhood type and parent-reported IM were also significant predictors, suggesting that living in urban environments or with fewer parent-imposed mobility restrictions, may facilitate the ability to journey further from home. Parent's perception of neighborhood risk, while not exhibiting a strong direct correlation with MPD, surfaced as a significant predictor; children of parents who perceived lower risk are more likely to travel further. Environmental conditions made only a modest contribution to the model, but higher proportions of commercial land within $800 \mathrm{~m}$ also predict an increased likelihood of travel further from home. While not a strong predictor model overall, analysis suggests that individual, perceptual, and built environmental factors are influencing the extent of a child's neighborhood travel boundary and the size of their frequented activity space. 
Table 6. Linear Regression Model 2: Proportion of Time Spent Within $400 \mathrm{~m}$ of Home.

\begin{tabular}{|c|c|c|c|}
\hline Independent variables & Unstandardized $\beta$ & Standardized $\beta$ & $95 \% \mathrm{Cl}$ \\
\hline Age group (9-II/I2-13 years) & -0.03 & $-0.18^{\dagger}$ & {$[-0.06,0.00]$} \\
\hline $\begin{array}{l}\text { Travel mode to/from school } \\
\text { (active/non-active) }\end{array}$ & 0.06 & $0.37 * * *$ & {$[0.03,0.09]$} \\
\hline $\begin{array}{l}\text { Parent-reported independent } \\
\text { mobility (low IM/high IM) }\end{array}$ & -0.04 & $-0.21^{*}$ & {$[-0.08,-0.01]$} \\
\hline$\%$ industrial land within $800 \mathrm{~m}$ & 0.00 & $0.22^{\dagger}$ & {$[0.00,0.01]$} \\
\hline$\%$ residential land within $800 \mathrm{~m}$ & 0.00 & $0.33^{*}$ & {$[0.00,0.00]$} \\
\hline$\%$ agricultural land within $800 \mathrm{~m}$ & 0.00 & $0.30 *$ & {$[0.00,0.00]$} \\
\hline
\end{tabular}

$n=108$

Adjusted $r^{2}=.254$

$t_{p}<.10 . * p<.05 . * * p<.01 . * * * p<.001$.

Model 2: Proportion of time spent within $400 \mathrm{~m}$ of home. The strongest regression model for predicting the proportion of time a child will spend within 400 $\mathrm{m}$ of their home (adjusted $r^{2}=.254$ ) also included variables from more than one variable set (see Table 6). Travel mode to school was again the strongest predictor, this time favoring the non-active travelers; children who do not regularly travel on foot or bicycle to school were more likely to be found in their NAS very close to home. As with distance traveled, higher mobility restrictions also predict that children are more likely to spend their NAS time within $400 \mathrm{~m}$ of home. Age group was also predictive; younger children (9-11 years old) were more likely to spend a greater proportion of their time close to home. Unlike the MPD model, however, none of the child or parent neighborhood perception variables strongly predicted the proportion of time spent near home and the extent of the child's habitual activity space. More built environment variables, however, were predictive in this second model. The proportion of industrial, residential, and agricultural land uses within $800 \mathrm{~m}$ were all positive predictors of time spent within $400 \mathrm{~m}$ of home; that is, the higher the proportion of any of these land uses, the more likely the child would be found within just a short distance of their home.

\section{Discussion}

How Far From Home Are Children Traveling, and How Large Is Their Frequented Activity Space?

An examination of the spatial extents of children's NAS revealed that many children are traveling significant distances from home, close to $1 \mathrm{~km}$ on 
average, at least on occasion. These measures represent significant pedestrian-based journeys and define relatively long, if not wide, frequented NAS for many of the participants. Evidence of these more distant trips are encouraging when compared with recent studies suggesting many children are not traveling more than a few hundred meters from home (Shaw et al., 2012; Veitch et al., 2008). These longer trips, even if infrequent, expose child travelers to a range of neighborhood experiences that can support their healthy development.

More distressing is the revelation that almost one quarter of the children did not "actively" travel more than $400 \mathrm{~m}$ from home at any time, and more than $15 \%$ did not venture more than $200 \mathrm{~m}$ from home during the entire study period. These very short distances suggest a significant portion of the participants have very small frequented activity spaces, limited to the area immediately around their homes, and in turn very little exposure to neighborhood settings. These smaller NAS may be related to perceptions of neighborhood risk; analysis suggests that distance traveled, and the level of independent mobility awarded to a child, is connected with a child's or a parent's impression of local risks to safe play and travel, regardless of whether they represent a true reflection of neighborhood barriers or hazards.

For many children, the journey to school is contributing in large part to their overall neighborhood journeys, or to facilitating higher degrees of independent mobility. Active travelers traveled almost twice the average distance of peers who are regularly driven or bussed to school. Although these longer journeys may be attributed in part to the active trip to school, they do not account for all NAS journeys; two thirds of the active travelers continued to destinations beyond their school. Regression analysis confirmed a very strong relationship between regular mode of travel to school and the distance children travel from home, consistent with other studies of children's mobility (e.g., Page et al., 2010; Villanueva, Giles-Corti, Bulsara, McCormack, et al., 2012). Active travel to school was also clearly linked to the distance from home to school, findings echoed in other travel studies (Larsen et al., 2009; McDonald, 2007a). The proportion of active travelers among those children living within $1,600 \mathrm{~m}$ of school $(80.7 \%)$ was 8 times higher than those living beyond $1,600 \mathrm{~m}$ from school $(9.8 \%)$. Children living within $1,600 \mathrm{~m}$ of their school also traveled almost $400 \mathrm{~m}$ more on average than those living further away. Shorter distances between home and school may make active travel to school not only more feasible but also more palatable for parents. Seeing their child handle the challenges of this active commute may in turn lead them to relax restrictions around other local journeys, extending the acceptable domain for neighborhood-based activities. Smaller home to school distances seem to facilitate both active travel to school as well as more frequent 
and distant neighborhood travel, thereby expanding the size of the child's frequented activity space.

Parent-awarded license to travel to school or to other destinations in the neighborhood also strongly predicted whether children actively traveled significant distances during the study period. Children with the highest IM levels demonstrated the longest average MPD of any demographic group. Previous research suggests children's IM level hinges partly on a parent's confidence in their child's ability to tackle the challenges they would likely encounter in their neighborhood (Valentine \& McKendrck, 1997; Villanueva, Giles-Corti, Bulsara, McCormack, et al., 2012). This confidence is reflected in the correlation of IM level with age group; as in other studies, older children generally experienced fewer mobility restrictions than their younger peers, presumably because parents are more comfortable granting increased freedom to children as they mature (Johansson, 2006; Spilsbury, 2005; Timperio et al., 2004).

Surprisingly, neither the child's age nor gender contributed in any significant or systematic way to the relative size of their NAS. However, parentreported IM and parent perception of neighborhood safety, strong predictors of distance traveled, were both highly correlated with age. Parents of younger children tended to impose more restrictions on unsupervised activity and were more likely to perceive risks associated with the neighborhood, both of which were associated with shorter distances traveled. The lack of genderrelated differences may be a reflection of a diminishing gap between males and females with respect to neighborhood independence and activity; however, it may also reflect decreases in mobility for all children, rather than increases in neighborhood freedom awarded to girls.

The built environment of the neighborhood is also playing a role in the distances children are traveling. There were no statistically significant differences in the average MPD traveled by urban versus suburban children, but the child's home neighborhood type did surface as significant predictor in regression analyses. These findings are consistent with a recent review of correlates with children's mobility (see Shaw et al., 2012), which suggest some attributes typically associated with urban environments, such as diverse land uses and more highly connected street networks, mayfacilitate local travel among children.

The proportion of commercial land within $800 \mathrm{~m}$ of a child's home also surfaced as a predictor of distance traveled. Examining the children's local environments in more detail revealed that most participants with the highest proportion of nearby commercial land reside in dense, older urban neighborhoods within close proximity to commercial corridors or clusters. A few meeting this criterion, however, live in less dense suburban environments, 
but on the edges close to major roads and clusters of commercial properties; while exhibiting many hallmarks of a typical suburban setting, their home location still provides them convenient and fairly direct access to commercial amenities similar to some of their urban peers. The proportion of nearby commercial land may also serve as a proxy for a more mixed-use environment in general, which can offer greater opportunities for and diversity of neighborhood activities. When neighborhood resources and amenities are available within a reasonable distance from home, they may succeed at drawing children further and more frequently into the neighborhood.

Relationships between the size of a child's NAS and local built environment conditions reinforces that a general neighborhood typology is not sufficient to characterize the influence of the local built environment on children's activity and movement. The strong correlations between distance traveled and the proportion of both commercial and agricultural land within the broader neighborhood suggests that those "suburban" neighborhoods located closer to the suburban-rural fringe, with fewer nearby commercial properties and more limited social and recreational opportunities within walking distance of home, need to be considered differently than "suburban" settings with higher residential density and nearby commercial centers. More comprehensive and nuanced descriptors of the neighborhood around children's homes are needed to understand the influence of nearby environmental conditions on local activity and mobility.

This analysis demonstrates that many participating children undertook significant pedestrian journeys, defining frequented NAS that extend a significant distance from their homes. The size of these frequented domains, however, varied substantially among participants; a number of children ever only ventured a short distance from home. More distant journeys into the neighborhood were most strongly influenced by individual-level factors, particularly active travel to school and higher independent mobility, but were also facilitated by parental perceptions, and built conditions, of the neighborhood environment.

\section{How Much Time Do Children Spend in Their Neighborhood Environments, and How Close To Home? How Large Is Their Habitual Activity Space?}

Understanding the degree to which children regularly utilize their neighborhood environments for activity requires that we consider not only how far they travel but also where they spend the bulk of their out-of-school time. Although many children exhibited fairly long pedestrian journeys, participants in general spent the vast majority of their NAS time inside or within 
very close proximity of their home and little relative time within the broader neighborhood environment. That is, although the size of some children's frequented activity spaces are reasonably large, their habitual activity spaces remain very small, the equivalent of just a few houses down the street from their home.

As with maximum distance traveled, active travel, living closer to school and a higher level of independent mobility all surfaced as predictors that a child would spend more of their NAS time at locations more distant from home. Active travel to school also seems to support additional neighborhood activity beyond the school journey itself; active travelers spent, on average, almost 7 times as much time beyond $800 \mathrm{~m}$ of home than did non-active travelers. These findings suggest that, when given the time and freedom, many children will take advantage of opportunities to explore and push the boundaries of their habitual activity spaces.

While child gender did not prove a significant factor, age group was a strong predictor of time spent at various distances from home, and was the lone significant factor explaining differences in time spent in the neighborhood beyond 1,600 $\mathrm{m}$ of home. Older children did not necessarily travel further distances on average, but they were significantly more likely to be found spending time within settings beyond $800 \mathrm{~m}$ of home. The proportion of time older children spent in more distant settings was not substantial relative to all time within their NAS but there was still a noticeable presence, whereas very few younger participants spent any time in settings beyond $800 \mathrm{~m}$ of home. These findings are in keeping with trends that see greater license being granted to older children, but may also reflect a natural interest in exploring environments further from home as children mature and gain a greater sense of environmental competence.

It was expected that parent perceptions of the neighborhood, particularly of its potential risk to a child, would predict whether a child spends their time closer to home; the lack of association is surprising given the influence of parent perceptions on the distances children traveled. Parent perceptions of risk were, however, highly correlated with age, as were parent-imposed mobility restrictions; risk perception, and the IM restrictions they can generate, may be more influential with respect to independence granted to younger children. Parents may be less concerned about an older child's ability to cope with dangers posed by the neighborhood. Children's neighborhood perceptions also correlated with time spent close to home but were not as strongly predictive as parental mobility restrictions. That is, an anxious child may not push the boundaries of their neighborhood domain even when granted permission to do so, but many children may not even have this choice if their neighborhood mobility has already been limited by parents. However, a 
child's age, and age-related perceptions of neighborhood risk, account for more variance in time spent close to home than either child or parent perceptions alone.

Local built environment conditions also contributed to the relative time children spent in their NAS, but in different ways than they influenced distance traveled. Neighborhood type was no longer a strong environmental predictor; however, higher proportions of industrial, residential, or agricultural land within $800 \mathrm{~m}$ of home predicted a child would more likely spend time within $400 \mathrm{~m}$ of home. Given the negative correlation between residential density and time spent close to home (see Table 2), the positive relationship with the proportion of nearby residential land is perplexing until we more closely examine the home neighborhoods of children with high levels of nearby residential land. While children from both "urban" and "suburban" neighborhoods fell into this category, their immediate environments were characterized by similar built conditions; each child appeared to live in a "residential island," surrounded primarily by homes and some recreational parkland, but located far from any commercial clusters or corridors. GPS tracking confirmed that these children largely confined their pedestrian activities to their residential neighborhood and nearby parks, staying very close to home. One of two phenomena is likely at work here. First, as suggested by Villanueva, Giles-Corti, Bulsara, McCormack, et al. (2012), the proximity of many homes and potential playmates, as well as the substantial recreational lands nearby, may satisfy many of the child's play interests and reduce the need to travel further afield. Alternatively, the locations of commercial or other recreational properties that might normally be of interest are considered to be too far or too few for comfortable and convenient access. This is supported by the correlation between higher levels of commercial properties beyond $800 \mathrm{~m}$ of home and greater time spent in more distant settings. In either case, children living in either urban or suburban "residential islands" exhibited small habitual activity spaces.

Similarly, the local neighborhoods of children registering high proportions of either industrial or agricultural land nearby were all bordered by a wide swath of one of these land uses on one or more sides, which were often aligned with restrictive morphological elements, such as railroad lines or major arterial roads, reinforcing the mobility barrier presented by these land uses. These environmental conditions serve to not only limit children's movement to but a few directions from home but also effectively reduce the number of appealing recreational and social opportunities within the immediate vicinity. Whether influenced by high proportions of nearby residential, industrial, or agricultural lands, the behavior patterns of affected children accentuate the influence of environmental conditions and morphologies of the near 
neighborhood on local travel and activity. These results also reinforce earlier remarks advocating for better and more nuanced characterizations of children's local built environments.

This analysis illustrates that participant children spent the majority of their pedestrian-based leisure time at or within very close proximity to home. It is also likely that the majority of this NAS time was spent indoors at home, and that most children's habitual out-of-school activity space extends only occasionally into neighborhood domains, if at all. For the small amount of time that is spent in the neighborhood beyond the home, select individual-level variables and built environment conditions appear to most influence levels of local activity.

\section{Efficacy of NAS Conceptual Models and Metrics}

One goal of this study was to develop and test the value of a new conceptual model and its associated metrics for quantifying GPS-based NAS and examining children's local activity and mobility. Moore's model of nested domains proved valuable as a foundation for conceptualizing and quantifying spatial and spatio-temporal measures of GPS-derived activity spaces, and establishing children's habitual and frequented activity spaces. The developed metrics proved effective for revealing how far children are traveling within local environments as well as where they spend the bulk of their leisure time. These complementary measures also allow us to examine differing neighborhood behaviors, and to explore the diverse conditions that underscore them. Both the conceptual model and the metrics presented are valuable additions to the growing field of GPS behavior tracking and to the expanding body of work seeking to capture and examine children's neighborhood domains and behaviors.

\section{Limitations}

Although this study makes significant advances toward conceptualizing and measuring children's NAS and examining the time children spend in local environments, the small sample size makes multivariate and regression analyses difficult, and limits us to preliminary exploration of individual- and environmental-level differences in local behavior. Continued work with larger participant samples and a broader or more nuanced set of variables will shed light on the relationship between children's behavior and their neighborhood environments, as well as the mediating effects of individual, perceptual, and environmental factors. The GPS data collected for this study also do not reveal whether children's neighborhood activity was independent, that is, 
without adult supervision. As well as not knowing "with whom" they are conducting their activities, GPS data alone cannot reveal exactly "what" children are doing, or "why." To more fully understand children's neighborhood behavior, we must supplement such analyses with deeper explorations of children's activities, patterns in adult or peer accompaniment, and the motivations or interests that underscore neighborhood use.

\section{Conclusion}

An increasing number of studies from developed countries are highlighting a dramatic and disturbing decline in contemporary children's neighborhood activity and mobility. This examination of the NAS of children in London, Canada, reveals similar reductions in habitual activity spaces, and generally low levels of neighborhood use. While participants spent more than $75 \%$ of their out-of-school time on average within their NAS, most spent more than half of this time indoors at home. Many children exhibited some ability to travel to relatively distant destinations within their neighborhood, some more than $1 \mathrm{~km}$ from home, but still spent very little time overall venturing into community settings beyond just a short distance of home. This is not surprising given that the vast majority of participants were subject to household rules that restrict unsupervised neighborhood travel, and which effectively limit activity to a very narrow geography immediately around their homes. The powerful influence of these parent-imposed restrictions was clearly evident, as children with fewer mobility restrictions tended to travel further, have larger NAS, and spent more time in more distant environments than their lower mobility peers. The result is that the habitual activity spaces of participating children were generally very small and concentrated indoors at home, with few children traveling more than a few hundred meters beyond home during their free time.

Although behavior patterns across participants were highly variable, findings clearly illustrated the strong influence of other individual-level factors on local activity and travel, particularly with respect to age and travel mode to school. Neighborhood design and built environment conditions within the broader community, while not generally as influential as compositional factors, still played a significant role in broadening or constricting children's habitual and frequented activity spaces. Some variance can be explained by differences that broadly typify urban and suburban environments; however, examinations of neighborhoods on a micro-scale revealed that the specific environmental amenities and morphological conditions immediately surrounding a child's home proved a greater influence on local behavior and mobility. Future studies should direct more attention to the specific features 
and layout of the child's near neighborhood, rather than rely on simplified neighborhood typologies.

Time and freedom to play outdoors and explore the diverse, stimulating settings of the neighborhood are critical for children's healthy development. Lack of exposure to the challenges of new environments can handicap a child's ability to develop skills and insights that will promote their continued health and well-being. The more children learn to negotiate new settings and situations, the more knowledge they gain of place, including its inherent hazards, and the better adapted they become to deal with its challenges. The contemporary notion of appropriate play, however, has become sanitized from which most, if not all, risk has been removed. This includes severely limiting unsupervised neighborhood play, and increasing levels of structured and indoor activity. Use of these protective strategies is not new; however, what may be changing is the degree to which these restrictions are being employed in children's daily lives. As is reflected in this study, contemporary children appear to be rapidly losing the opportunity to play freely, unsupervised, and unstructured, in the diverse environments of their neighborhood. We see this particularly in the diminutive habitual NAS of the child participants.

The significant influence of the active journey to school on increasing both the distance children travel and the time they spend playing in neighborhood environments provides a strong indicator of where we might start to target our efforts to reverse the alarming trends reflected in this study. In addition to the benefits of active travel to school for the physical health of children, this journey may act as a springboard to increasing both child and parent comfort with neighborhood play and travel in general, which can support a wide range of healthy developmental activities. Policy and planning efforts should be directed toward supporting a child's ability to walk or bike to their school, including the provision of a supportive, "walkable" environmental infrastructure.

The last few decades have been witness to substantial changes in the overall structure and rhythms of children's daily lives as well as their primary environmental settings, yet little attention has been paid to the health impacts of these changes, particularly with respect to the decline of neighborhood activity and mobility. The alarming consequences for children's healthy development and well-being require not only that we advance research that seeks to understand the factors influencing children's local behaviors, but that citizens, designers, and politicians step up both practice and policy efforts to promote the necessity of local activity for children's health, and to provide them with access to safe, diverse, and supportive neighborhood environments. 


\section{Acknowledgments}

The authors would also like to thank the students, parents, and staff of the London District Catholic School Board as well as staff and students of the Human Environments Analysis Laboratory of Western University.

\section{Declaration of Conflicting Interests}

The author(s) declared no potential conflicts of interest with respect to the research, authorship, and/or publication of this article.

\section{Funding}

The author(s) disclosed receipt of the following financial support for the research, authorship, and/or publication of this article: This research was funded by the Social Sciences and Humanities Research Council of Canada, Canadian Institutes of Health Research and the Canadian Heart and Stroke Foundation.

\section{References}

Bartlett, S., Hart, R., Satterthwaite, D., De La Barra, X., \& Missair, A. (1999). Cities for children: Children's rights, poverty and urban management. London, UK: Earthscan.

Buliung, R. N., Mitra, R., \& Faulkner, G. (2009). Active school transportation in the Greater Toronto Area, Canada: An exploration of trends in space and time (19862006). Preventive Medicine, 48, 507-512.

Burdette, H. L., \& Whitaker, R. C. (2005). A national study of neighborhood safety, outdoor play, television viewing, and obesity in preschool children. Pediatrics, $116,657-662$.

Chawla, L. (1992). Childhood place attachments. In I. Altman \& S. M. Low (Eds.), Human behavior and environment: Advances in theory and research (Vol. 12; pp. 63-86). New York, NY: Plenum Press.

Churchman, A. (2003). Is there a place for children in the city? Journal of Urban Design, 8, 99-111.

Clements, R. (2004). An investigation of the status of outdoor play. Contemporary Issues in Early Childhood, 5, 68-80.

Cliff, D. P., Reilly, J. J., \& Okely, A. D. (2009). Methodological considerations in using accelerometers to assess habitual physical activity in children aged 0-5 years. Journal of Science and Medicine in Sport, 12, 557-567.

Colley, R., Gorber, S. C., \& Tremblay, M. S. (2010). Quality control and data reduction procedures for accelerometry-derived measures of physical activity. Health Reports, 21(1), 63-69.

Copperman, R. B., \& Bhat, C. (2009, July). Children's activity-travel patterns and implications for activity-based travel demand modeling. Austin, TX: Center for Transportation Research.

Fagerholm, N., \& Broberg, A. (2011). Mapping and characterising children's daily mobility in urban residential areas in Turku, Finland. Fennia International Journal of Geography, 189(2), 31-46. 
Frank, L. D., \& Engelke, P. O. (2001). The built environment and human activity patterns: Exploring the impacts of urban form on public health. Journal of Planning Literature, 16, 202-218.

Fyhri, A., \& Hjorthol, R. (2009). Children's independent mobility to school, friends and leisure activities. Journal of Transport Geography, 17, 377-384.

Fyhri, A., Hjorthol, R., Mackett, R., Fotel, T. N., \& Kyttä, M. (2011). Children's active travel and independent mobility in four countries: Development, social contributing trends and measures. Transport Policy, 18, 703-710.

Gaster, S. (1991). Urban children's access to their neighborhood. Environment and Behavior, 23, 70-85.

Gill, T. (2007). No fear: Growing up in a risk averse society. London, England: Calouste Gulbenkian Foundation.

Gray, P. (2011). The decline of play and the rise of psychopathology in children and adolescents. American Journal of Play, 3, 443-463.

Hart, R. (1979). Children's experience of place. New York, NY:Halsted Press.

Hillman, M., Adams, J., \& Whitelegg, J. (1990). One false move. London, England: Policy Studies Institute.

Johansson, M. (2006). Environment and parental factors as determinants of mode for children's leisure travel. Journal of Environmental Psychology, 26, 156-169.

Karsten, L. (2005). It all used to be better? Different generations on continuity and change in urban children's daily use of space. Children's Geographies, 3, $275-$ 290.

Kerr, J., Frank, L. D., Sallis, J. F., \& Chapman, J. (2007). Urban form correlates of pedestrian travel in youth: Differences by gender, race-ethnicity and household attributes. Transportation Research Part D: Transport and Environment, 12, 177-182.

Kerr, J., Rosenberg, D., Sallis, J. F., Saelens, B. E., Frank, L. D., \& Conway, T. L. (2006). Active commuting to school: Associations with environment and parental concerns. Medicine \& Science in Sports \& Exercise, 38, 787-794.

Kyttä, M. (2004). The extent of children's independent mobility and the number of actualized affordances as criteria for child-friendly environments. Journal of Environmental Psychology, 24, 179-198.

Larsen, K., Gilliland, J., Hess, P., Tucker, P., Irwin, J., \& He, M. (2009). The influence of the physical environment and sociodemographic characteristics on children's mode of travel to and from school. American Journal of Public Health, 99, 520-526.

Loebach, J., \& Gilliland, J. (2010). Child-led tours to uncover children's perceptions and use of neighborhood environments. Children, Youth \& Environments, 20(1), $52-90$.

MacDougall, C., Schiller, W., \& Darbyshire, P. (2009). What are our boundaries and where can we play? Perspectives from eight to ten year old Australian metropolitan and rural children. Early Child Development and Care, 179, 189-204.

Macintyre, S., \& Ellaway, A. (2000). Ecological approaches: Rediscovering the role of the physical and social environment. In L. F. Berkman \& I. Kawachi (Eds.), Social epidemiology (pp. 332-348). New York, NY: Oxford University Press. 
Mackett, R., Brown, B., Gong, Y., Kitazawa, K., \& Paskins, J. (2007). Children's independent movement in the local environment. Built Environment, 33, 454-468.

Matthews, H. (1992). Making sense of place: Children's understanding of large-scale environments. Hemel Hempstead, UK: Harvester Wheatsheaf.

McDonald, N. C. (2007a). Children's mode choice for the school trip: The role of distance and school location in walking to school. Transportation, 35, 23-35.

McDonald, N. C. (2007b). Travel and the social environment: Evidence from Alameda County, California. Transportation Research Part D: Transport and Environment, 12, 53-63.

McDonald, N. C., Brown, A. L., Marchetti, L. M., \& Pedroso, M. S. (2011). U.S. school travel, 2009 an assessment of trends. American Journal of Preventive Medicine, 41, 146-151.

McMillan, T. E. (2007). The relative influence of urban form on a child's travel mode to school. Transportation Research Part A: Policy and Practice, 41, 69-79.

Mikkelsen, M. R., \& Christensen, P. (2009). Is children's independent mobility really independent? A study of children's mobility combining ethnography and GPS/ mobile phone technologies. Mobilities, 4, 37-58.

Moore, R. (1986). Childhood's domain: Play and place in child development. London, UK: Croom Helm.

Page, A. S., Cooper, A. R., Griew, P., \& Jago, R. (2010). Independent mobility, perceptions of the built environment and children's participation in play, active travel and structured exercise and sport: The PEACH Project. The International Journal of Behavioral Nutrition and Physical Activity, 7, Article 17.

Pallant, J. (2011). SPSS survival manual: A step by step guide to data analysis using SPSS (4th ed.). Buckingham, UK: Open University Press.

Panter, J. R., Jones, A. P., \& van Sluijs, E. M. (2008). Environmental determinants of active travel in youth: A review and framework for future research. The International Journal of Behavioral Nutrition and Physical Activity, 5, Article 34.

Penpraze, V., Reilly, J. J., MacLean, C., Montgomery, C., Kelly, L., \& Paton, J. Y. (2006). Monitoring of physical activity in young children: How much is enough? Pediatric Exercise Science, 18, 483-491.

Pooley, C. G., Turnbull, J., \& Adams, M. (2005). The journey to school in Britain since the 1940s: Continuity and change. Area, 37, 43-53.

Prezza, M., \& Pacilli, M. G. (2007). Current fear of crime, sense of community, and loneliness in Italian adolescents: The role of autonomous mobility and play during childhood. Journal of Community Psychology, 35, 151-170.

Prezza, M., Pilloni, S., Morabito, C., Sersante, C., Alparone, F. R., \& Giuliani, M. V. (2001). The influence of psychosocial and environmental factors on children's independent mobility and relationship to peer frequentation. Journal of Community \& Applied Social Psychology, 11, 435-450.

Rissotto, A., \& Giuliani, M. V. (2006). Learning neighborhood environments: The loss of experience in a modern world. In C. Spencer \& M. Blades (Eds.), Children 
and their environments: Learning, using and designing spaces (pp. 75-91). Cambridge, UK: Cambridge University Press.

Rissotto, A., \& Tonucci, F. (2002). Freedom of movement and environmental knowledge in elementary school children. Journal of Environmental Psychology, 22, 65-77.

Sallis, J. F., \& Glanz, K. (2006). The role of built environments in physical activity, eating, and obesity in childhood. Future of Children, 16(1), 89-108.

Schoeppe, S., Duncan, M. J., Badland, H. M., Oliver, M., \& Curtis, C. (2013). Associations of children's independent mobility and active travel with physical activity, sedentary behavior and weight status: A systematic review. Journal of Science and Medicine in Sport, 16(4), 312-319.

Shaw, B., Watson, B., Frauendienst, B., Redecker, A., Jones, T., \& Hillman, M. (2012). Children's independent mobility: A comparative study in England and Germany (1971-2010). London, UK: Policy Studies Institute.

Spilsbury, J. (2005). "We don't really get to go out in the front yard"-Children's home range and neighborhood violence. Children's Geographies, 3, 79-99.

Timperio, A., Crawford, D., Telford, A., \& Salmon, J. (2004). Perceptions about the local neighborhood and walking and cycling among children. Preventive Medicine, 38, 39-47.

Valentine, G., \& McKendrck, J. (1997). Children's outdoor play: Exploring parental concerns about children's safety and the changing nature of childhood. Geoforum, 28, 219-235.

Veitch, J., Salmon, J., \& Ball, K. (2008). Children's active free play in local neighborhoods: A behavioral mapping study. Health Education Research, 23, 870-879.

Villanueva, K., Giles-Corti, B., Bulsara, M., McCormack, G. R., Timperio, A., Middleton, N., . . Trapp, G. (2012). How far do children travel from their homes? Exploring children's activity spaces in their neighborhood. Health \& Place, 18, 263-273.

Villanueva, K., Giles-Corti, B., Bulsara, M., Timperio, A., McCormack, G. R., Beesley, B., . . Middleton, N. (2012). Where do children travel to and what local opportunities are available? The relationship between neighborhood destinations and children's independent mobility. Environment and Behavior, 45, 679-705.

Witten, K., Kearns, R. A., Carroll, P., Asiasiga, L., \& Tava'e, N. (2013). New Zealand parents' understandings of the intergenerational decline in children's independent outdoor play and active travel. Children's Geographies, 11, 215-229.

Wridt, P. (2010). A qualitative GIS approach to mapping urban neighborhoods with children to promote physical activity and child-friendly community planning. Environment and Planning B: Planning and Design, 37, 129-147.

\section{Author Biographies}

Janet E. Loebach completed her doctorate in geography at Western University, with an interdisciplinary focus on children's health-related behaviors and their everyday environments. She is a registered professional engineer with a master's degree in environmental design. Her ongoing research and consulting efforts focus on the 
assessment, programming, and evidence-based design of environments for special populations, including children, older adults, and those with special needs. She is particularly interested in utilizing participatory processes to evaluate and improve community environments. Janet is currently a post-doctoral fellow with the Young Lives Research Lab at the University of Prince Edward Island.

Jason A. Gilliland is the director of the Human Environmental Analysis Laboratory and associate professor of geography at Western University. He is also a scientist with the Children's Health Research Institute and Lawson Health Research Institute. His ongoing research focuses on aspects of urban planning and development, urban design, transportation, children's geographies, and public health in Canadian cities. $\mathrm{He}$ is particularly interested in advancing urban and health applications of geographic information systems (GIS). 